\title{
Practice on CSU-CCECC-ABU Cooperation Mode
}

\author{
Atolagbe Shakirudeen Olabanji Xuhui $\mathrm{He}^{*}$ Bin Yan \\ School of Civil Engineering, Central South University, Changsha, Hunan, 410075, China
}

\begin{tabular}{l} 
ARTICLE INFO \\
Article history \\
Received: 17 July 2021 \\
Revised: 25 July 2021 \\
Accepted: 15 October 2021 \\
Published Online: 30 October 2021 \\
\hline
\end{tabular}

Keywords:

Educational cooperation

Joint degree

Practice

Student exchange

Internationalization

\begin{abstract}
Student exchange program has been an integral part of higher education, which is popularly known as international joint-, double-, and combineddegree programs, which perform an important role in which its strategic plan is aimed to allow students to become true global citizens. Educational Internationalization strategy brings important benefits to individuals, institutions, and the nation's education systems. The international student exchange program is not only a powerful tool in strengthening the relationship between two institutions but also helps in building the social, political, and economic development of the partner nations. Also, it is among the most cost-effective ways to project influence around the world. Educational collaboration on student exchange has had a beneficial impact on the status of any country, institution, and students, influencing society at its prominent backdrop for only favourable outcomes and a brighter future. CSU-CCECC-ABU collaboration was the first of its kind, and it was in accordance with both institutions' missions to encourage collaborative innovation to address the needs and problems of Nigeria, the People's Republic of China, and the rest of the globe.

This paper first outlined the background concepts and explicitly analyzed the pattern of cooperation practice, research on the National, University, and Students benefits respectively. Second, it provided a comprehensive description of challenges faced by exchange students during their stay in China. Third, suggestions were also provided on how to improve and sustain the educational cooperation practice of the joint degree program. Furthermore, it provides the current status of the CSU-CCECC-ABU cooperation practice. Finally, the paper provides directions to subsequent research studies.
\end{abstract}

positive externalities that promotes economic, social, political, and technological change ${ }^{[1,2]}$.

According to Sheriff's report, For any country to strike a balance between infrastructural development and human development, it is essential to invest in education ${ }^{[3]}$. Education is an excellent tool for the holistic development of human beings, as it makes use of the entire body to attain a predetermined set of goals.

Joining a student exchange or study abroad program for a semester or two is one of the most efficient ways

*Corresponding Author:

Xuhui He,

School of Civil Engineering, Central South University, Changsha, Hunan, 410075, China;

Email:xuhuihe@csu.edu.cn 
for students to get foreign experience. Such programs assist students in becoming multilingual individuals with intercultural abilities, as well as in forming long-lasting connections with people from other nations, all of which contribute to world peace ${ }^{[4]}$. Universities are attempting to extend their student exchange programs and encourage their students to join as a result of these benefits. As a basis, they must prepare their students for intercultural competence and foreign profession ${ }^{[5]}$. Institutions, programs, and courses should be positioned to contribute to the internationalization of higher education and to prepare students for global markets. An internationalized curriculum, according to the Organization for Economic Cooperation and Development (OECD), is one that has a "international orientation in context, aimed at preparing students for performing in a competitive and dynamic context, and designed for domestic as well as international students ${ }^{[6]}$."

According to Knight ${ }^{[7]}$, After completing the collaborative program requirements defined by partner schools, a joint degree program awards one joint qualification. The cooperating institution awards only one qualification in this area of collaborative program. However, due to limitations such as non-recognition and acceptance of the certificate stamp by two different universities, a double degree program is offered instead. Upon completion of the program requirements set up by the partner universities, the double degree program awards two individual qualifications at an equivalent level. This is practice in almost all the regions in the world such as the US which is in partnership with countries like China, France, Turkey, Germany, and South Korea among others ${ }^{[8]}$. Universities all over the world are also involved in research collaboration, which is a means of generating and exchanging ideas, methodology, and results among academics, industry scientists, and government scientists ${ }^{[9]}$.

China's strategy plan for education internationalization includes collaborative degree and research programs to strengthen links and transfer home technology to other nations for the common good. The Chinese government authorizes and encourages a strong-strong partnership model of Sino-foreign colleges to expedite education opening up and bring in more high-quality international educational resources ${ }^{[10]}$. According to the Ministry of Education of the People's Republic of China, collaborations with over 180 nations or regions have resulted in the establishment of 2,385 collaborative educational institutions and initiatives, as well as 8 high-level people-to-people exchange schemes. While collaborative degree programs between China and other advanced economies with world-class universities have existed for some time, China has recently expanded its partnership to developing nations, allowing students from other countries to pursue their study in China. More partnerships are being formed as a result of China's development, particularly to efforts like the Forum on China-Africa Collaboration, which are directed by ChinaAfrica strategy. The research partnership between China and Africa has increased as a result of such initiatives, from a few hundred publications in 2006 to over 2000 in $2016^{[11]}$. China annually awards scholarships to around 1,500 African students, and several Chinese colleges have formed links with African institutions ${ }^{[12]}$. Because of China's research capacity, a collaboration between China and other institutions across the world would contribute to the development of research capacity and output dedicated to improving university rankings ${ }^{[13]}$.

In the last decade, Nigeria's relationship with China has expanded. Aside from commerce, foreign direct investment, and financing, educational cooperation has emerged as a key component of the China-Africa framework. As a result, it is impossible to underestimate the significance of education. It develops, shapes, and even transforms you. The number of people who are educated determines a country's influence. In Nigeria, however, the government only set out 7.04 percent of the 8.6 trillion Naira budget for education. As a result, China is extending its educational collaboration with Nigeria through the Forum on China-Africa Cooperation (FOCAC) framework in order to close the skills and educational gap in Nigeria and assure sustainable growth.

According to Edeh's report, the FOCAC educational agenda has grown to include technical and vocational education and training, distance learning (remote learning), school construction, volunteer dispatch, and teaching Chinese as a foreign language ${ }^{[14]}$.

Educational cooperation has become an essential aspect of the China-Nigeria framework to strengthen both nations' ties with the agenda of working together for common development and a shared future, and this will be explored to the extent that the character of China's aid policy, generally, are often, illustrated by its education and training policies and practices. (FOCAC 2009) ${ }^{[15]}$.

In line with the China-Africa framework, in early 2017 during the Federal executive council meeting, the Minister of Transportation made a pronouncement on the partnership strategy to establish the University of Transportation in Nigeria to provide the manpower required for Rail Mass Transit development, as well as to develop future railway infrastructure and to speed up professionals for massive transportation investment in the railway, airport and roads development. It was from 
this approach, $\mathrm{ABU}$ was picked out of seven Nigerian universities to begin the joint degree program which was dubbed ' $3+\mathbf{2}$ ' (three years in ABU plus two years in Central South University, Changsha) in railway and transportation engineering with China's Central South University (CSU), Changsha. The process began and a team from Central South University (CSU), Changsha, China paid a visit to verify the kind of institution $A B U$ was and check the modalities upon which the exchange program will be built. It wasn't so long, the company who has been in charge of Railway Infrastructure construction in Nigeria (China Civil Engineering Construction Corporation, CCECC) was also charged by the ministry of transportation to also be a part of the collaboration since its part of the agreement made in the contract project between the Federal government of Nigeria. Therefore, CCECC came up on board and firstly facilitate the visit of $\mathrm{ABU}$ delegates to $\mathrm{CSU}$ to establish various aspects of the collaboration. The visit enabled all involved parties to have a very long discussion and negotiations, although there were issues of understanding such as knowing respective institutions strengths and academic capacity but in the long run, it was settled and they were able to formulate the whole framework of the collaboration on the $3+2$ joint degree program. Afterward, a Memorandum of Understanding (MOU) was signed in December 2017 by all parties involved and this is what gave birth to the practice of CSU-CCECC-ABU Educational exchange cooperation. First of its kind in Nigeria and Africa at large ${ }^{[16]}$.

As a citadel of learning, $\mathrm{ABU}$ considered the situation and the trend of the event in the transportation sector particularly the railway technology, took advantage of the government commitment to revive the railway sector, and then conceived the $3+2$ program.

Establishing a joint program is far more than entering into a contract. It encompasses developing a new study program and a new arena for knowledge. The fundamental goal of building joint programs is to advance the standard of the education and research the degree encompasses. The possible outcome of two or more institutions joining forces to offer a study program should be a program of a higher academic standard than the institutions would achieve independently. However, this kind of collaboration brings about important strategic, scholastic, and practical encounters, particularly when legislative and educational structures differ. The work is demanding and time-consuming and there is a need for support to be able to create well-integrated programs and of the highest quality ${ }^{[17]}$.

This paper first outlined the background concepts and explicitly analyzed the pattern of cooperation practice, research on the National, University, and Students benefits respectively. Second, it provided a comprehensive description of challenges faced by exchange students during their stay in China. Third, suggestions were also provided on how to improve and sustain the educational cooperation practice of the joint degree program. Furthermore, it provides the current status of the CSUCCECC-ABU cooperation practice. The conclusion was drawn from the discussions in the paper and there was a provision of directions for further research in the future.

\subsection{Basic Terms and Concepts}

\subsubsection{Joint Study Programme}

According to the definition of European Higher Education which is straightforward and appears to fit the area's reality. However, it may be too simple to convey the reality's complexities. As a result, a more precise definition of a joint program can be devised. "An integrated curriculum organized and offered jointly by several higher education institutions and resulting in a (double/multiple or joint) degree" ${ }^{[18]}$.

\subsubsection{Joint Degree Program}

"A joint degree is cited a educational capability issued jointly by a minimum of two or more higher education institutions, or jointly by one or more educational activity institutions and other granting bodies, based on a study program developed and/or provided jointly by the higher education institutions," according to a strong recommendation from scholars ${ }^{[19]}$.

\subsubsection{Dual Degree Program}

Dual degree programs are planned and offered by two or more partner institutions in separate nations, according to the US criteria. The student receives a diploma from each of the partner institutions at the conclusion of the program. "Double" degrees are another term for such programs ${ }^{[8]}$.

\subsubsection{Memorandum of Understanding (MOU)}

A Memorandum of Understanding (MOU) could be a formal, lawful document between two or more parties that shapes a partnership/collaboration. This is steady with the University of Chicago's definition. Depending on the interests of the person or group establishing the agreement, each active MOU serves a specific purpose visiting scholar exchanges, student exchanges, resource sharing, and so on. It should be noted that unless the parties expressly specify that they do not intend to be 
legally bound by the conditions of an MOU, it will be regarded as a binding agreement ${ }^{[20]}$.

A Memorandum of Understanding (MOU) is a document that sets forth the parties' broad understanding of the fundamental aspects that will eventually be agreed upon, according to another definition from an organization. A Memorandum of Understanding should be written once the institutions have agreed on the general structure for the intended collaboration. This document may or may not be legally binding, depending on the parties' wishes, though it may become legally binding inadvertently. A Memorandum of Understanding has no defined format, and whether it contains details of the parties' ideas or only the major elements necessary to move the negotiations forward is a matter of personal preference and pragmatism. As a general rule, the Memorandum of Understanding should cover the transaction's most important provisions. Drafting concerns can be discussed later, but they should be avoided at this juncture $^{[21]}$.

\subsubsection{Bachelor Degree Exchange Program}

Students from two universities in two separate countries can participate in an exchange program, which permits them to spend two or more semesters taking classes at the other university. Students from the "home university" spend a limited amount of time as visiting students at the "host institution" to get foreign experience. A student exchange agreement between the two colleges allows for this strategy to be implemented. For undergraduate students to be eligible for an exchange program, home universities typically have a minimum grade point average (GPA) requirement. Additionally, the students must meet the host university's basic standards. A minimum GPA or a certain degree of fluency in the host country's language are examples of these requirements. For a long-term agreement, the number of students in each university's exchange program should be roughly equal in both directions. The arrangement may come to an end if an approximate balance is not met over a period of time ${ }^{[22]}$.

\subsubsection{University-Industry Cooperation Practice}

Plewa and Quester define university-industry partnerships as "trusting, committed, and interactive interactions between university and industry organizations that enable the transmission of creativity, ideas, skills, and people across time to produce mutual benefit" ${ }^{[23]}$.

Educational programs, student employment, consultancy work, and research ${ }^{[24]}$ are the four basic types of partnerships with industry that have been identified.
Students, professors, educational programs, research output, and university reputation all gain from collaboration with industry.

Students, faculty, and the university as a whole benefited from collaborations with industry. Gaining practical skills, increased work chances, and, in a few programs, extra certification of their talents by the company were all highlighted as advantages for students. Employer participation in education was seen as critical to attaining high-quality, relevant information and skills. Improved expertise, particularly in practical elements of their field, enhanced financial benefits, and the ability to influence government policies, particularly for those involved in formulating and amending government policies and legislation, are all advantages for faculty ${ }^{[24]}$.

Partnerships between universities and industries are becoming more important in the innovation process. To boost their regional innovation systems, regional policymakers are designing policy instruments to facilitate knowledge transfer between science and industry. The widespread acceptance of the non-linear model of innovation to explain the innovation process in innovation studies has given rise to this policy trend ${ }^{[25]}$.

\subsection{Aims and Objectives of the CSU-CCECC- ABU Educational Cooperation}

\subsubsection{Aim}

The Joint-Double Bachelor of Engineering Degree program is the result of strategic thinking by $A B U$ academics, and the partnership is primarily focused on the following areas:

(1) In the shortest period possible, it's proposed to have developed indigenous railway technology and manpower in Nigeria.

With these new graduates trained in two worlds and armed with top-notch skills, it is hoped that Nigeria will lead African nations in the development of railway technology and toward the realization of the African Union's vision 2040 of creating an integrated highspeed train network that connects all African capitals and commercial centers, facilitating the movement of goods, people, and capital.

(2) Developing technically proficient and well-rounded engineers with strong technical abilities and a thorough awareness of the context concerns surrounding sustainable development and the environment in which they work.

\subsubsection{Objectives}

The following are the specific goals of the joint degree program:

DOI: http://dx.doi.org/10.26549/jetm.v5i2.7745 
(1) It will provide an excellent opportunity to fill up the gaps in the field of railway engineering. Because it is in line with the Federal Government of Nigeria's development agenda, it has considerable government support.

(2) It aims to give students with specific skills and a solid foundation for future growth and development in Engineering by providing education in basic sciences, engineering sciences, and humanities and social sciences that are important to engineering applications.

(3) To provide key manpower for the Nigerian train's development. To offer courses that focus on providing students with the knowledge necessary to enter a variety of disciplines of transportation engineering such as Highway Engineering, Railway Engineering, Airport Engineering and, Port and Harbor Engineering, Structural Engineering, Bridge Engineering, Traffic Equipment, and Control.

(4) To prepare graduates to improve their skills in relevant transportation engineering specialties.

(5) To develop high-quality engineering graduates who can adapt to the workplace and carry out their responsibilities ethically while adhering to worldwide norms.

(6) To prepare students for careers in engineering through a dual/internationalized environment.

\section{Operational Principles of the Educational Cooperation}

\subsection{Exchange Program Coordinators}

All departments participating in the Bachelor's degree student exchange program are required to nominate an exchange coordinator who is a faculty or staff member from that department ${ }^{[22]}$. The tasks of an exchange program coordinator are elaborated as follows:

- Enlighten the students in the department about the exchange system and the partner institutions.

- Maintain constant communication with the coordinators of the partner universities' exchange programs.

- To inform possible exchange students of the department, the exchange coordinator must review the regulations, academic rules, and courses of the appropriate departments in partner universities.

- Provide students with information about courses available at partner universities. Students must know how they will satisfy the requirements of their home institution with the courses they study at the host university before they left for the host nation. It is unfavourable if courses taken abroad do not count toward the home institution's degree requirements.

- Serve as a point of contact for departing students and be available for academic advice.

- When the leaving exchange students return, report the grades of the courses they took abroad to the department, maybe after converting them using an equivalency.

\subsection{Credit Transfer for Bachelor's Degrees}

Different institutions may have differed grading policies. As a result, some institutions only use the number of completed courses at the host university toward graduation requirements at the home institution, and the beneficiaries are exempt from equally as many courses in the curriculum of their home university. The grades earned during the exchange period, on the other hand, will not be factored into the home institution's computation of the student's grade point average. Some institutions, on the other hand, may decide to use a grade equivalency table to transfer the courses and their grades. Before going on an exchange, students should be aware of the ramifications of the exchange system and the marks they will receive overseas ${ }^{[22]}$.

\section{The Benefits of the Educational Cooperation}

Collaborative-degree programs have had a significant impact, resulting in a stronger and longer-lasting relationship than many other internationalization strategies, as well as academic benefits such as curriculum innovation, professor and researcher exchange, and increased access to expertise and research networks.

For students who want to go on an international experience, student exchange offers a variety of perks and consequences. The majority of these are linked and combine to form the overall exchange experience ${ }^{[26]}$.

The majority of international students studying in other countries come from developing countries with the goal of obtaining a high-quality education that is often superior to that available in their own country. When international students return home, they can make a substantial contribution to the growth of their home country. International students who receive an international education can contribute to their nations' economic and social development by utilizing newly acquired scientific and technological knowledge and skills ${ }^{[13]}$. The university, students, and the nation have all benefited from educational partnership.

\subsection{National Benefits}

Higher education international collaborations boost 
the national economy significantly. They are considered as contributing to enhanced status, competitiveness, and capacity building at the national level, which helps to improve intellectual dialogues and generate novel solutions for addressing national concerns ${ }^{[27]}$. This partnership was purely for the purpose of developing Nigeria's and Africa's infrastructure systems. This student exchange practice, according to Hallet, helps to connect students in order to foster cooperation and development on the global concerns of economic, environmental, and international relations ${ }^{[28]}$.

\subsection{University Benefits}

Education cooperation yields a benefit to the university in helping to broaden research capacities, enhanced powers to recruit talented international students and faculty, and a more visible and global research profile.

In the past few years, educational cooperation between Chinese universities has paid off by raising the teaching and research levels of China's university teachers, hastening the development of key and new fields of study and key laboratories, assisting in the resolution of technical issues in research work, and cultivating topnotch innovative and competitive professionals ${ }^{[29]}$. A large number of countries urge their universities to expand their international student and exchange student populations, not to raise university profits, but to nurture soft power and, as a result, increase international trade between the countries ${ }^{[22]}$.

However, statistics reveal that approximately 300 Chinese institutions are working together with over twenty multinational firms to produce computer hardware and software, as well as teach students in related technology and accreditation. These exchanges have increased these universities' international collaboration opportunities, improved their teaching environments, aided in the development of their information programs, cultivated software engineers, and accelerated the development of computer and networking technology in this country ${ }^{[29]}$.

The enhanced usage of information technology in today's environment promotes arrangements among higher educational institutions around the world in terms of knowledge and research transfer and adaptation. An increasing number of contacts with other regions of the world are formed through university-based international relations centers, which contribute to international funding, teacher/student interaction, and the development of international exchange and master's programs ${ }^{[30]}$.

The invention of educational cooperation which brings about the practice of CSU-CCECC-ABU is a great development and innovation because the host institutions
(CSU) that have collaborated is the best school and the kind that have high-level quality particularly railway and transportation engineering. This cooperation will create an avenue to train engineers equipped with the appropriate knowledge and skills required for effective operation and management of the transportation industry, a key sector for the rapid diversification of the Nigerian economy and Africa at large. Also, it will foster global recognition to the institution and help to speed up development in the area of the railway research area.

\subsection{Students Benefits}

Graduates with degrees from two separate nations have been a step ahead of the competition in the international labor market in recent years. Students pursue double degrees for a variety of reasons, including increased employment options, international study and living experience, and the belief that earning two degrees for the price of one implies less effort ${ }^{[27]}$. Potential employers will place a high value on international experience, not just in terms of business but also in terms of life skills. Students have a more international classroom experience, which provides them with a more diverse learning experience. Educational collaboration encourages students to be more conscious of cultural diversity, embrace it, and build their cultural capital. Students also get the opportunity to go to different countries, study and master the local language, develop self-confidence, and prepare for diversity.

Students are encouraged to appreciate and understand a diverse range of cultural and community perspectives through international learning and information ${ }^{[26]}$. When it comes to dealing with global concerns, students learn a new viewpoint. Exchange programs provide opportunity for students to learn, develop, and collaborate with others to tackle common challenges and safeguard their futures. Student exchange programs develop future leaders who understand the need of international collaboration, comprehension, and empathy on an abstract level.

\section{Challenges of Educational Exchange Programs}

Although it is simple to plan and develop a university's physical environment to match international standards, international students studying in China nonetheless encounter a number of problems ${ }^{[31]}$.

\section{Language barrier}

The most prevalent barrier for students who desire to study in China or elsewhere is the language barrier. When you study in China, you will be confronted with the difficulty of learning the Chinese language, which is one of the most difficult languages in the world ${ }^{[32]}$. Foreign students have long struggled with language obstacles, 
which make communication difficult both in the classroom and in their social lives. Furthermore, several important educational websites and materials are only available in Chinese, making it difficult for international students to access them for academic purposes. International students, on the other hand, have noted that forming friendships is difficult owing to the cultural gap. However, attempts have been made to improve connections between Chinese and international students by attempting to match students with comparable backgrounds and experiences to make it easier for them to strike up conversations and build friendships.

\section{Cultural Shock}

The culture of each country is distinct. Because China has the world's largest population, it is well renowned for its vast cultural diversity. You'll need to acclimate to the local culture in addition to learning the language and currency. This also implies the presence of a wide range of cultures ${ }^{[33]}$. Many students experience some form of "cultural shock" as a result of their studies. The cuisine offered, for example, could be the most challenging component of their stay, contributing to cultural shock. This shock may manifest as feelings of annoyance, anxiety, or rage, a lack of motivation, or a persistent feeling of illness. All of these feelings are common when transitioning to a new way of life. It's possible that the adjustment time will be difficult ${ }^{[22]}$. It is our obligation to strive to comprehend these distinctions and blend in as soon as possible. The culture here is warm and hospitable; it's a lovely country with a fascinating culture.

\section{Separation of Chinese and international students}

In terms of intercultural encounters and language interchange, the international student is disadvantaged by the separation of international and Chinese students' dormitories. Interacting with Chinese people is one of the primary goals of student mobility to China. Separating international and Chinese students, on the other hand, will make it difficult for international students to adapt to Chinese culture and improve their language skills. Having some classes together will improve the exchange of ideas and approaches, as well as allow Chinese and international students to collaborate on research. On both sides, this will serve to foster academic brilliance. However, international hostels and Chinese hostels should be partnered in such a way that they share common rooms for relaxation, interactions, and even studies to strengthen their bond, rather than sharing the same bedrooms. In addition, games and other events between the international and Chinese dorms might be held on a regular basis to improve student relations. All of these things will assist international and Chinese students better understand one other's cultures and build togetherness ${ }^{[31]}$.

\section{Changes in teaching methodology}

Changes in teaching methodology influenced and affect exchange/International students by historical/ cultural and geographical/environmental factors. All of this is attributable to their diverse backgrounds and social systems.

Students' achievement and teacher evaluation are directly influenced by changes in teaching methodology. The focus and difficulty of education mechanism reform has been attributed to the reform of school teaching methods. Unlike the Chinese system of education where the emphasis is laid more on fractional theories and results that inhibit nature, the exchange students are from where a large number of students of high-end talents are under pressure and more emphasis is laid on examination-oriented education. Generally, China's teaching methodology lay more emphasis more on an understanding of knowledge, implement a strict and stable classroom organization model but the west-African laid more emphasis on student's individuality towards innovation.

In this regard, to improve the overall quality of exchange students, to cultivate and create a multi-faceted talent, the exchange students are encouraged to quickly adapt to this reform.

Those changes in teaching methodology practice help to assess the overall level of students with comprehensive quality and also eliminate the emergence of the highscore low-energy phenomenon. However, the educational exchange cooperation between institutions from different countries will bring progress and strengthen individual school involves to make up adjustments to their teaching plan in line with international practice, it will also promote the students physical and mental development, so overall essence will be achieved and they truly become the backbone of their country.

\section{Recommendations in Sustaining the Practice of Educational Cooperation Programs}

To make this practice a long-lasting one, the host university needs to put some sustainable measures into consideration for the progress of the program. Below are some of the measures as follows:

1) The host university should form and develop a "international office" to handle full-time overseas students 
as well as exchange students. The obligation for recruiting such students should fall to this office. It should also assist exchange students in obtaining visas or permits to stay in the country. To expedite the bureaucratic process, the student's home nation should contact the embassy of the host country. In a nutshell, the international student office should be in charge of everything pertaining to international and exchange students.

2) During the exchange students' first week, the international office should conduct orientation activities for them. Printed documents, booklets, or links to online pages that provide important information to the exchange students during their first challenging weeks should be distributed by the office throughout this program. The information package should include information about the university's history as well as information about campus life, entertainment venues, concert halls, museums, local currency, banking, food, cafes, pubs, restaurants, sports facilities, course registration methods, grading and credit systems, course registration methods, the library, computer facilities, traffic restrictions, shopping, places of worship, bookstores, safety concerns, health care, the smoking policy, medical insurance, housing, transit, parking, useful websites, and travel information are all available.

3) During the first week, the international office should host a welcoming reception. This can help exchange students get off to a good start by allowing them to meet other exchange students as well as local students

4) The international office should develop and maintain a well-maintained website for exchange students. For example, the WeChat group, which may also be used to disseminate information

5) The foreign office should plan cultural outings to adjacent locales. Archaeological sites, museums, and touristic/historic neighbouring cities or regions, for example, may be suitable options.

6) The international office should make the academic rules and regulations known to the students. They should be informed of the repercussions of examination misconduct and plagiarism.

7) The international office should educate students about the country's laws. It may not be permitted to engage in activities such as drug usage, clubbing, and so forth.

8) The university should provide international students local language classes. Instead of a complete academic language course with grammar, reading, and writing components, such courses should be intended to be useful in everyday life with an emphasis on vocabulary and pronunciation components.

9) The international office should give psychological assistance to students experiencing culture shock or other difficulties.

10) The international office should hold frequent social activities that bring together domestic and international students. Students who have already participated in foreign exchange programs may be invited to such events since they are typically more inclined to participate. It's also a good idea to plan a social farewell celebration for exchange students departing for their home countries at the conclusion of the semester.

International students have unique demands that should not be overlooked by the host university. Exchange students may have problems if there is no international office or if the international office isn't doing its job correctly. The importance of visiting students' brand awareness in establishing the university's reputation should not be underestimated ${ }^{[22]}$.

\section{Current Status of the CSU-CCECC-ABU Cooperation Practice}

Between 2018 and 2021, 123 students have been enrolled for the undergraduate level, and 17 academic staff from the Faculty of Engineering for the MSc and Ph.D. study.

Currently, 74 students have so far graduated from this cooperation. 50 of the students currently admitted to CSU to further their Master's degree education owing to the steering performance of the students during the undergraduate. The remaining students are currently undergoing a 1-year internship program in various railway construction sites in Nigeria with CCECC.

The academic staff is also growing annually with many of them nearing completion of their various post-graduate programs.

Sequel to the outbreak of the pandemic, the two schools (CSU-ABU) involved plans to explore the possibility of a lecturer's exchange where teachers from CSU will teach in $\mathrm{ABU}$ for some time and $\mathrm{ABU}$ teachers will also teach in CSU for the same period with a view of boosting and sustaining the existing cooperation practice between the two prestigious institutions.

The COVID-19 pandemic resulted to closure of borders by almost all the countries which brought the economy of most nations to a standstill. The rate and number of COVID-19 infections in the world forced many countries to close their schools with the sole aim of preventing the spread and transmission of COVID-19 to the university populations and eventually to the communities. To prevent a total shutdown of the educational sector, universities shift from in-person teaching activities to virtual classrooms. This also led to cancellation of many 
international and local conferences and workshops which was also turned virtual later. However, due to the adverse effect of the game-changer, COVID-19, some of the undergraduate students are running their program virtually from their home country and the program which is always conducted annually was put on hold until further notice.

With time, the Nigerian students are getting more accustomed to the life and culture of their host community and the program can be said to have been overall successful.

\section{Conclusions}

The Chinese government has established a number of scholarship programs to fund overseas students, teachers, and intellectuals to study and do research in Chinese institutions to foster mutual understanding, cooperation, and exchanges in different disciplines between China and other countries. The inclusion of foreign exchange students in a university classroom increases classroom diversity and student contact with people from various cultures, allowing students to build their intercultural competences and become global citizens.

Scholarships awarded by the Chinese government to international students have absolutely attracted a large number of international students, resulting in a significant growth in the number of foreign students in China.

Universities, in addition to government actions, play an important role in attracting overseas students ${ }^{[31]}$. The presence of international students and the contributions alumni make across the world, according to Rowan (1993), can boost institutions' international credibility ${ }^{[34]}$. Problem-solving, decision-making, leadership styles, thinking and reasoning processes, and communication styles are all reflected pattern that are internationally represented by foreign students ${ }^{[35]}$.

$\mathrm{CSU}$ is among the few locations in the world that has a solid reputation and provides high-quality engineering education, notably in the areas of railway and transportation engineering. As a result, educational background can help with worldwide career prospects, which also functions as a draw factor. CSU has an established connection with international institutions and an annually signed agreement for exchange students, in addition to growing its impact. Technology advancements make studying and accessing more relevant academic material easier and more comfortable for foreign students. Most Chinese universities and other international institutions, specifically in developed nations, are expanding their exchange programs and cooperative academic research initiatives dramatically. As part of their internationalization drive, several Chinese institutions are currently holding foreign conferences, academic workshops, and seminars. These activities, as well as an understanding of other foreign universities' programs and degree requirements, allow Chinese universities to maintain the integrity of their curriculum, pedagogical approaches, and degree requirements, while also allowing them to collaborate closely with their international counterparts ${ }^{[31]}$.

This paper first outlined the background concepts and explicitly analyzed the pattern of cooperation practice, research on the National, University, and Students benefits respectively. Second, it provided a comprehensive description of challenges faced by exchange students during their stay in China. Third, suggestions were also provided on how to improve and sustain the educational cooperation practice of the joint degree program. Furthermore, it provides the current status of the CSUCCECC-ABU cooperation practice.

To summarize, because China is currently attracting a large number of international students, it is encouraged that more quality be added to higher education in the areas of pedagogy and research work in order to attract a large number of brilliant international students and strengthen international cooperation. ABU students have expressed interest in the combined degree. We are extremely lucky to be one of the beneficiaries of this collaboration practice, despite some of the obstacles. I hope the ideas offered are implemented and sustained to keep this cooperation practice going for a long time.

Future study should concentrate on strategies to improve foreign students' relationships with research supervisors, as this is preventing students from participating in academic work that might improve their abilities and widen their perspectives.

\section{References}

[1] F. H. Harbison, "Human resources as the wealth of nations," 1973.

[2] F. A. Sanubi and N. E. Akpotu, "The Nigeria Education System and Vision 20: 2020--A Critical Development Planning Perspective [J].," Int. J. Educ. Adm. policy Stud., vol. 7, no. 2, pp. 26-38, 2015.

[3] Sherif, "HISTORY OF EDUCATION IN NIGERIA-Development since 1960 till date \& Before Independence," Nigeria, 2020. [Online]. Available: naijaquest.com.

[4] W. J. Clinton, "Executive Memorandum on US International Education Policy for the Heads of Executive Departments and Agencies," The White House, 2000.

[5] A. E. Fantini, F. Arias-Galicia, and D. Guay, Global- 
ization and 21st century competencies: Challenges for North American higher education. Western Interstate Commission for Higher Education Boulder, CO, 2001.

[6] S. Parham, "Organization for Economic Co-operation and Development (1996) Innovative Policies for Sustainable Urban Development." OECD Publishing.

[7] J. Knight, "Student Mobility and Internationalization : trends and tribulations," vol. 7, no. 1, pp. 2033, 2012.

DOI: 10.2304/rcie.2012.7.1.20.

[8] U. S. P. Profiles, "Mapping International Joint and Dual Degrees :"

[9] K. Ukrainski, J. Masso, and H. Kanep, “Cooperation patterns in science within Europe : the standpoint of small countries," pp. 845-863, 2014.

DOI: $10.1007 / \mathrm{s} 11192-013-1224-0$.

[10] J. Zheng and D. Kapoor, "State formation and higher education ( HE ) policy : an analytical review of policy shifts and the internationalization of higher education ( IHE ) in China between 1949 and 2019," 2020.

[11] W. Eduan and J. Yuanqun, "Patterns of the China-Africa research collaborations from 2006 to 2016 : a bibliometric analysis,” no. 19, pp. 979-994, 2019.

[12] R. Yang and A. Welch, "A world-class university in China ? The case of Tsinghua," no. July 2011, pp. 645-666, 2012.

DOI: $10.1007 / \mathrm{s} 10734-011-9465-4$.

[13] J. Kaur, N. Singh, and G. Jack, "The benefits of overseas study for international postgraduate students in Malaysia," pp. 607-624, 2018.

DOI: 10.1007/s10734-017-0159-4.

[14] E. E. Chidiebere, "Advancing China and Nigeria educational cooperation," 2018. [Online]. Available: chinadaily.com.cn.

[15] F. (Forum on China-Africa, "Implementation of the Follow-up Actions of the Beijing Summit of the Forum on China-Africa Cooperation, FOCAC, 10 November 2009," Beijing, 2010. [Online]. Available: http://www.focac.org/eng/dsjbzjhy/hywj/t627504.

[16] "From ABU to China," vol. 5, no. 2, 2018.

[17] "GUIDE TO DEVELOPING AND RUNNING JOINT PROGRAMMES AT BACHELOR AND MASTER'S LEVEL - A template."

[18] A. Aerden and H. RECZULSKA, "European Consortium for Accreditation in higher education." Comisión Europea, Dirección General de Educación y Cultura, 2010.
[19] A. Rauhvargers, "Improving the recognition of qualifications in the framework of the Bologna Process," Eur. J. Educ., vol. 39, no. 3, pp. 331-347, 2004.

[20] "Establishing a Memorandum of Understanding," UChicago Global, 2021. https://global.uchicago.edu/ faculty/establishing-memorandum-understanding.

[21] CHRISTIAN, "AGREEMENT OF COOPERATION BETWEEN UNIVERSITIES," AALEP, 2019. http:// www.aalep.eu/agreement-cooperation-between-universities.

[22] A. Atalar, "Student exchange: The first step toward international collaboration" [J] in Successful Global Collaborations in Higher Education Institutions, Springer, 2020, pp. 63-71.

[23] C. Plewa and P. Quester, "A dyadic study of 'champions' in university $\square$ industry relationships," Asia Pacific J. Mark. Logist., 2008.

[24] D. Jonbekova, J. Sparks, M. Hartley, and G. Kuchumova, "International Journal of Educational Development Development of university [J] - industry partnerships in Kazakhstan : Innovation under constraint," Int. J. Educ. Dev., vol. 79, p. 102291, 2020. DOI: 10.1016/j.ijedudev.2020.102291.

[25] "INDUSTRY COLLABORATION A Policy Brief from the Policy Learning Platform on," no. January, 2020.

[26] "BENEFITS OF STUDENT EXCHANGE," WEP, 2021. https://wep.org.au/student-exchange/benefits-of-student-exchange/.

[27] P. W. Definitions and T. Future, "Programs : Double Benefits or Double Counting”, 2013.

[28] "The Value of Student Exchanges to Developing Countries," USAID, 2017. https://medium.com/usaid-2030/the-value-of-student-exchanges-to-developing-countries-and-the-u-s-3909b22e9986.

[29] "International Cooperation and Exchange," ENCYCLOPEDIA, 2019. https:/www.encyclopedia.com/ international/news-and-education-magazines/international-cooperation-and-exchange\#B.

[30] E. Conference and H. Education, "Internationalisation and the Role of University Networks Proceedings of the 2009 EMUNI Conference on Higher Education and Research Portorož, Slovenia, 25-26 September,' High. Educ., vol. 20, no. October, pp. 25-26, 2009 , [Online]. Available: http://www.heacademy.ac.uk/ assets/York/documents/ourwork/research/surveys/ PGTSurvey.pdf.

[31] F. O. Larbi and W. Fu, "Practices and challenges of internationalization of higher education in China; in- 
ternational students' perspective: A case study of Beijing Normal University," Int. J. Comp. Educ. Dev., vol. 19, no. 2-3, pp. 78-96, 2017.

DOI: 10.1108/IJCED-12-2016-0025.

[32] Sam, "Challenges Faced by Students in China," 2020. https://aljawaz.com/en/challenges-faced-bystudents-in-china/.

[33] J. Jiyagatai, "Challenges Faced by International Students in China," Greener J. Educ. Res., vol. 8, no. 4, pp. 065-075, 2018.
DOI: 10.15580/gjer.2018.4.051118070.

[34] R. Rowan, "The attitudes and opinions of international students studying in the College of Education at the University of Minnesota," Unpubl. master's thesis, Univ. Minnesota, Minneap., 1993.

[35] J. Mestenhauser, "Internationalization at home: Rethinking campus internationalization," [J] Michigan State Univ. http/www. isp. msu. edu/international, 2005. 